Cytosquelette,

\section{moteurs}

moléculaires

et développement

Nous parlions récemment

dans ces colonnes de l'importance

de l'asymétrie en biologie

du développement, base

de l'établissement des axes

de morphogenèse. En réalité,

celle-ci s'établit très tôt,

au niveau cellulaire: l'ovocyte,

puis l'auf unicellulaire,

sont polarisés, ce qui implique

une répartition anisotrope

de leurs constituants dont la

partition va aboutir à la création

de régions, de "pôles" à l'origine

du développement ultérieur,

notamment de la distinction

entre germen et soma. La nature

des signaux initiaux aboutissant

à l'asymétrie cellulaire reste

mal conmue; elle est probablement

diverse: interaction avec les cellules

voisines durant l'ovogenèse,

pénétration du spermatozoïde

peuvent intervenir. Le tri,

puis la répartition anisotrope

des constituants ovocytaires

dépend du cytosquelette -

microtubules, fibres d'actine

- et des moteurs moléculaires,

les utilisant pour transporter

protéines et $A R N$ vers leur site

spécifique, pôle animal ou pôle

végétatif. Il semble qu'alors ces

différentes macromolécules,

déterminants du destin des régions

où elles sont localisées, soient prises

en charge par le cytosquelette

sous-membranaire qui doit donc

être, lui aussi, très tôt spécialisé.

Ainsi, la surface d'un ouf

presque sphérique contientelle,

imprimée, la carte

du devenir de l'embryon.

Ce sont encore ces systèmes

-fibres et microtubules, moteurs moléculaires, squelette

sous-membranaire - qui règlent

ultérieurement la polarité

des cellules épithéliales

et leurs échanges

avec l'extérieur par pinocytose,

endocytose et exocytose.

\title{
Cytosquelette et polarité ovulaire
}

\author{
Herman Denis
}

La grande majorité des métazoaires

produisent des æufs qui sont

visiblement polarisés. Le plus

souvent, l'œu a une forme

sphérique, mais possède deux pôles

distincts, appelés animal et

végétatif. Plus rarement, l'œuf a une

forme allongée, qui préfigure celle de

l'embryon. Puisqu'elle est générale,

on peut supposer que la polarité

ovulaire constitue un caractère

primitif, acquis par un ancêtre

commun des métazoaires actuels.

Selon toute vraisemblance,

ce lointain précurseur ne comportait

que deux catégories de cellules:

germinales et somatiques. Au cours

du développement, la différenciation

des cellules en deux types dépendait

de facteurs localisés dans

le cytoplasme de l'œuf, reflet

d'une organisation polarisée.

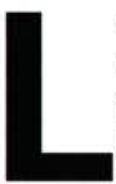

a plupart des métazoaires recourent à la reproduction sexuée. Ils se développent à partir d'un œuf, fruit de l'union de deux cellules sexuelles: le spermatozoïde et l'ovule. Un œuf typique de métazoaire se présente comme une cellule de grande taille, de forme sphérique ou ovoïde. Puisque l'embryon et l'adulte ne sont jamais sphériques, il est clair que le développement fait perdre à l'ouf la symétrie inscrite initialement dans sa forme. Cette rupture de symétrie pose
La polarité ovulaire s'instaure

presque toujours pendant

l'ovogenèse. Elle tire probablement

son origine de la dissymétrie

qu'impose à toute cellule animale

la position du centrosome par

rapport au noyau. Le couple

centrosome-noyau aurait induit

dans un ovocyte de forme sphérique

une organisation bipolaire,

déterminant un axe

animal-végétatif. Le pôle animal est l'endroit près duquel se place le noyau de l'ovocyte, et où seront émis les globules polaires. Le pôle végétatif se forme du côté où se trouve le centrosome. C'est là que l'ovocyte aurait concentré, par un système lié au cytosquelette, des macromolécules aptes à promouvoir dans l'embryon la formation des cellules reproductrices.

des problèmes redoutables, dont la solution se dessine peu à peu.

\section{Polarité ovulaire et spécification de la lignée germinale}

Un œuf même parfaitement sphérique est une cellule anisotrope. Il possède de nombreuses dissymétries. La plus visible se manifeste par l'existence de deux pôles d'aspect différent, que l'on appelle animal et végétatif. 
Dans de nombreux groupes zoologiques, la polarité de l'œuf influence le développement précoce de l'embryon en imposant l'émergence rapide de deux lignées cellulaires, dénommées germen et soma. La lignée germinale se spécialise dans la reproduction, tandis que la lignée somatique prend en charge toutes les autres fonctions corporelles (locomotion, capture et digestion des proies, etc.) [1].

Chez divers animaux tridermiques (amphibiens anoures, céphalochordés, insectes, chétognathes, nématodes), la lignée germinale se forme par un mécanisme relativement simple. L'œuf contient un ensemble de macromolécules, appelées déterminants germinaux, qui sont localisées dans une région définie du cortex, désignée par le terme de plasme germinal $[2,3]$. Les déterminants confèrent à la région de l'œuf où ils se trouvent une certaine autonomie en matière de différenciation. Cette propriété se révèle quand on réalise des destructions ou des transplantations de territoires ovulaires ou embryonnaires. Certains déterminants germinaux seraient des ARN [2]. Lors de la segmentation, les déterminants germinaux se répartissent entre les blastomères. Les cellules germinales dérivent des blastomères ayant incorporé une partie de ces déterminants. En dépit de nombreux travaux consacrés à leur sujet, on ne sait pas très bien comment les déterminants germinaux entraînent les cellules qui les intègrent à se différencier en gonocytes, puis en spermatozoïdes ou en ovules [2].

Chez le xénope, la drosophile et le nématode Caenorhabtitis elegans, le plasme germinal renferme des particules de nature ribonucléoprotéique, connues sous le nom de granules polaires (chez les deux premiers animaux) ou de granules $\mathrm{P}$ (chez C. elegans). Ces granules peuvent être observés au microscope électronique [2]. De nombreuses mitochondries leur sont associées. Si l'on irradie le plasme germinal de l'œuf d'amphibien ou d'insecte par un faisceau de lumière ultraviolette, l'embryon ne forme pas de gonocytes, ou n'en forme qu'un nombre réduit [2]. La

les ARN présents dans les granules germinaux.

\section{Polarité ovulaire et morphogenèse somatique}

La polarité de l'œuf revêt une grande importance non seulement pour la formation de la lignée germinale, mais aussi pour la morphogenèse somatique. Dans presque tous les groupes zoologiques que l'on a explorés, on a pu mettre en évidence un rapport entre la polarité de l'œuf et la polarité primaire de l'embryon et de l'adulte [4]. Chez de nombreux animaux didermiques, l'axe animalvégétatif de l'œuf coïncide avec l'axe oral-aboral du futur organisme, fixé par la position de la bouche [5]. Chez beaucoup de tridermiques, le pôle animal de l'œuf définit l'extrémité antérieure de l'embryon, tandis que le pôle végétatif définit l'extrémité postérieure [4].

Il arrive que la forme de l'œuf permette d'y reconnaître facilement l'axe primaire de l'embryon. Par exemple, l'œuf de la grande majorité des insectes est allongé et son grand axe coïncide avec l'axe antéro-postérieur de l'animal $[4,6]$. Chez la drosophile, on admet que le pôle postérieur de l'œuf correspond au pôle végétatif dans les œufs de forme sphérique [7].

\section{Nature de la polarité ovulaire}

Comment se manifeste la polarité ovulaire? Pour la décrire, l'ovocyte d'amphibien constitue un excellent modèle (figure 1). La polarité de l'ovocyte apparaît à l'œil nu ainsi qu'à l'examen de coupes histologiques. Des méthodes plus élaborées mettent en évidence d'autres dissymétries. Le pôle animal se situe au centre d'une zone pigmentée. C'est à son voisinage immédiat que se trouve le noyau (souvent appelé vésicule germinative), et que seront émis les globules polaires. Le plasme germinal réside à proximité du pôle végétatif.

L'hémisphère animal est plus riche en vésicules lipidiques que l'hémisphère végétatif, tandis que ce dernier renferme la plus grande partie des réserves vitellines. L'hémisphère végétatif est donc le plus dense, si bien qu'une fois fécondé et activé, l'œuf s'oriente dans l'eau en tournant vers le haut son pôle pigmenté. Une telle orientation offre deux avantages. En premier lieu, le pigment protège contre l'irradiation solaire l'ADN contenu dans la vésicule germinative. En deuxième lieu, il tend à rendre l'œuf peu visible sur le substrat où il repose, le dissimulant ainsi à ses éventuels prédateurs.

La distribution dissymétrique du vitellus influence celle des composants qui sont libres dans le cytosol. Les plaquettes vitellines étant moins grosses et moins abondantes dans l'hémisphère animal que dans l'hémisphère végétatif (figure 1 ), il existe à proximité du pôle animal davantage de cytoplasme dépourvu d'inclusions. Cela explique au moins en partie pourquoi certains composants (ribosomes, divers ARN messagers, granules de glycogène, etc.) y paraissent plus concentrés [10].

Le cortex végétatif de l'œuf contient non seulement les déterminants germinaux, mais aussi des molécules qui interviennent dans la morphogenèse somatique. Une expérience réalisée chez le xénope suffit à le montrer. Si l'on soumet le pôle végétatif de l'ovocyte ou de l'œuf à une irradiation ultraviolette, on inhibe non seulement la formation des cellules germinales, mais on perturbe aussi le déroulement de la gastrulation. Le traitement réduit la formation des structures antérieures et dorsales (notochorde et somites) [11]. Puisque la région du cortex proche du pôle végétatif contient d'autres déterminants que germinaux, il convient de l'appeler plasme polaire, plutôt que plasme germinal.

\section{Polarité ovulaire et méiose femelle}

On retrouve dans la plupart des œufs de forme arrondie les mêmes particularités structurales que dans l'œuf d'amphibien. En particulier, le vitellus se concentre dans l'hémisphère végétatif. $L a$ vésicule germinative se réfugie dans la région de l'ovocyte la moins chargée de vitellus, au voisinage immédiat du pôle animal [4]. 
Tout importantes qu'elles soient, ces deux particularités ne font que traduire deux modifications que les métazoaires primitifs ont apportées à la méiose femelle. L'une et l'autre ont pour effet d'accentuer l'anisogamie dont ces animaux ont hérité de leurs prédécesseurs unicellulaires, en favorisant la production de très gros ovules [12]. La première modification consiste à interrompre la prophase de la première division méiotique par une pause dont l'ovocyte profite pour s'accroître en accumu- lant des réserves vitellines. La seconde consiste à terminer la méiose par deux cytocinèses inégales. C'est la position excentrée du noyau qui rend possible la formation de deux cellules filles de tailles très différentes, dont l'une (le globule polaire) ne prélève qu'un minimum de cytoplasme à la surface de l'autre (l'ovocyte).

Pour produire de gros ovules, un moyen efficace est d'accumuler du vitellus. Plus l'ovocyte se charge de réserves vitellines, plus sa polarité

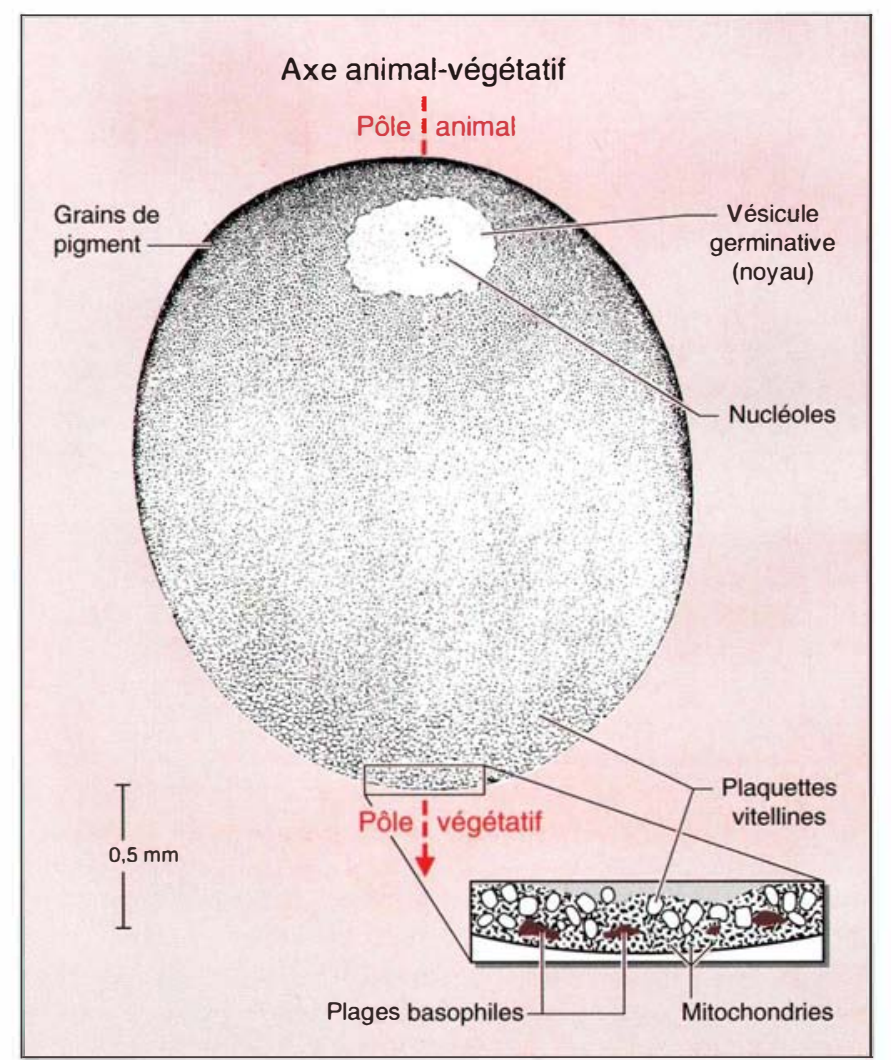

Figure 1. Polarité d'un ovocyte de grenouille (Rana sp.). Deux pôles nettement distincts apparaissent quand on pratique dans un ovocyte en fin d'accroissement une coupe passant par le pôle animal et le pôle végétatif. Tous les éléments figurés du cytoplasme sont distribués de manière dissymétrique. Les grains de pigment se localisent dans la partie superficielle de I'hémisphère animal. Leur extension ne dépasse guère l'équateur. La vésicule germinative se trouve à proximité du pôle animal, dans l'axe défini par les deux pôles. Les nucléoles sont rassemblés en son centre. L'hémisphère végétatif contient des plaquettes vitellines plus abondantes et plus grosses que l'hémisphère animal. La fenêtre montre une vue à fort grossissement de la région végétative $d^{\prime} u n$ œuf, après fixation et coloration par des procédés spéciaux. Cette région contient le plasme germinal. On y distingue de nombreuses mitochondries, ainsi que des plages basophiles. Au microscope électronique, ces plages apparaissent comme des zones riches en granulations opaques, appelées granules polaires. (D'après [8] et [9], modifié.) s'accentue. Dans les cas extrêmes (oiseaux, céphalopodes), la partie végétative de l'œuf devient gigantesque. Au début du développement, elle ne joue plus aucun rôle. C'est une masse inerte d'éléments nutritifs. L'embryon se développe sur cette masse, puis l'englobe et la digère peu à peu [10].

\section{Acquisition de la polarité ovulaire}

En général, la polarité de l'ovule apparaît bien avant la fécondation. Elle est déjà manifeste dans l'ovocyte en accroissement. C'est le cas pour les échinodermes, les vertébrés, les arthropodes, les mollusques, les annélides, etc. [4]. Il y a donc un délai entre l'établissement d'une polarité visible dans l'ovocyte et l'instauration d'une polarité perceptible dans la forme de l'embryon, puisque la morphogenèse ne débute qu'au moment de la gastrulation.

On connaît des exceptions à la règle énoncée ci-dessus. Chez le cténaire Beroe ovata ainsi que chez C. elegans, aucune polarité n'apparaît dans le cytoplasme de l'ovule. La fécondation déclenche des mouvements internes qui aboutissent à la mise en place des territoires destinés à construire les diverses parties de l'embryon [2, 13, 14]. C'est le spermatozoïde qui fixe l'axe oral-aboral ou antéro-postérieur de l'embryon et de l'adulte [13, 14].

Chez C. elegans, les mouvements intracellulaires contribuent à construire le plasme germinal. Distribués de manière assez uniforme dans le cytoplasme de l'ovule, les granules $P$ se concentrent après la fécondation au pôle postérieur de l'œuf [15]. Ce déplacement fait intervenir le cytosquelette, car il est inhibé par la cytochalasine D, qui dissocie les microfilaments, en favorisant leur dépolymérisation [15]. Puisque les granules se déplacent dans une direction définie, il est clair que le cytosquelette de l'œuf est polarisé.

\section{Polarité du cytosquelette}

Il n'y a pas que l'œuf qui ait un cytosquelette polarisé. Le cytosquelette de toutes les cellules eucaryotes pos- 
sède une polarité intrinsèque, qui dépend de la structure de ses deux éléments principaux: les microtubules et les microfilaments [16]. Ces fibres ont des extrémités dites $(+)$ et $(-)$, douées de propriétés différentes.

C'est la polarité des microtubules qui est la plus facile à reconnaître. Elle confère à toute cellule animale une anisotropie constitutive, que rend visible la position du centrosome par rapport au noyau. Le centrosome est un organite polarisé. Il constitue un centre organisateur des microtubules, couramment appelé MTOC (microtubule organizing center). Au microscope électronique, on y distingue une paire de centrioles, entourée d'un nuage de matériel opaque. Ce dernier contient un complexe de protéines (dont la tubuline $\gamma$ ), qui sont capables d'amorcer de manière unidirectionnelle l'assemblage des tubulines $\alpha$ et $\beta$ en microtubules [17]. Le MTOC organise les éléments instables que sont les microtubules d'une manière qui paraît uniforme chez tous les eucaryotes. L'extrémité dite (-) des microtubules se trouve au contact du centre nucléateur [16]. Elle possède une affinité plus faible que l'autre extrémité $($ dite + ) pour les sous-unités de tubuline. C'est donc l'extrémité $(+)$ qui est responsable de l'instabilité des microtubules: des sous-unités de tubuline s'y ajoutent et s'en soustraient continuellement [16]. Les microtubules s'associent à des moteurs (la kinésine et la dynéine), qui se déplacent vers leur extrémité $(+)$ ou (-) [18]. Toutes sortes de constituants s'attachent aux moteurs : protéines, ARN, organites $[16,19]$. Ils sont ainsi véhiculés suivant des voies fixées par l'orientation des microtubules.

En général, les microfilaments ont une polarité moins manifeste que les microtubules. Dans une cellule non épithéliale, ils sont disposés d'une manière assez uniforme [16]. Les microfilaments se composent essentiellement d'actine. Celle-ci s'ordonne en lacis ou en faisceaux de faible longueur, localisés principalement en périphérie du cytoplasme. Comme se construisent par recrutement d'unités globulaires [20]. La croissance se fait plus vite à l'extrémité dite barbelée (ou +) des filaments. Diverses protéines sont liées à l'actine [20]. Suivant leur nature, elles lui confèrent un rôle structural ou dynamique. Une couche réticulée de microfilaments forme un cortex soutenant la membrane plasmique [16]. L'actine peut s'associer à un moteur, qui est la myosine. En présence d'ATP, celle-ci se déplace dans une direction déterminée par rapport au filament d'actine [16].

\section{Polarité des cellules épithéliales}

Beaucoup de cellules animales font partie d'un épithélium. L'organisation épithéliale est la première qu'adoptent les cellules embryonnaires quand l'œuf se transforme en blastula. Tout cellule épithéliale est nettement polarisée. Elle a deux faces distinctes: une face apicale, tournée vers l'extérieur de l'organisme, et une face basale, tournée vers l'intérieur. La face apicale porte quelquefois des cils. La cellule possède alors plusieurs centres nucléateurs périphériques, puisque chaque cil porte à sa base un MTOC, que l'on appelle cinétosome. Dans une cellule épithéliale non ciliée, le centrosome se trouve à proximité de la face apicale et de nombreux microtubules sont orientés suivant l'axe basal-apical [16]. Quant au réseau cortical de microfilaments, il n'est pas réparti de manière uniforme, mais se concentre sous la paroi latérale et sur le pourtour de la face apicale, où il forme un anneau [16]. Ce dernier sert de point d'ancrage pour les jonctions intercellulaires, qui garantissent la cohésion de l'épithélium [16].

Les cellules épithéliales pratiquent souvent l'exocytose et l'endocytose. Ce dernier phénomène joue un rôle important au cours de l'ovogenèse. Dans un épithélium, c'est par leur face apicale que les cellules ingèrent les macromolécules présentes dans le milieu où elles baignent. L'intégration se fait au niveau de dépressions appelées puits recouverts, qui se creusent en permanence dans la membrane plasmique [16]. Les macromolécules se lient à des récep- teurs membranaires, qui se concentrent au niveau des puits. En se creusant et en se pinçant à leur base, les puits forment des vésicules qui se détachent de la membrane et pénètrent dans le cytoplasme. Le mouvement serait guidé et peut-être entraîné par les câbles de tubuline rayonnant autour du centrosome. Au sein du cytoplasme, les vésicules d'endocytose fusionnent avec d'autres vésicules dénommées endosomes. Les complexes ligand-récepteur aboutissent dans une troisième sorte de vésicules à contenu acide et riche en enzymes de dégradation : les lysosomes. Dans cet environnement destructeur, le complexe se dissocie et libère la macromolécule ingérée, tandis que le récepteur regagne la membrane plasmique à l'intérieur d'une vésicule animée d'un mouvement centrifuge [16].

\section{Détermination de la polarité ovulaire chez le xénope}

Comment s'organise le cytosquelette dans les ovocytes en accroissement? A cet égard, il convient de faire une distinction entre les animaux dépourvus de gonades et ceux qui possèdent des ovaires bien constitués. Chez certains animaux didermiques, comme les éponges calcaires, les ovocytes se développent librement parmi les cellules du soma [21]. Celui-ci ne semble jouer aucun rôle dans la détermination de la polarité ovulaire.

Chez tous les tridermiques, un ovaire recueille les ovocytes pendant qu'ils se différencient [21]. Toutefois, la gonade n'exerce pas toujours une influence décisive sur la fixation de l'axe animal-végétatif de l'ovocyte. C'est ce qu'on observe chez les vertébrés, et notamment les amphibiens tels que le xénope.

Dans l'ovaire adulte de cet animal, des ovogonies prolifèrent sans arrêt [22]. Quatre divisions successives créent un clone de 16 cellules sœurs, qui restent provisoirement unies par leur cytoplasme (figure 2). Quand elles abordent la prophase de la première division méiotique, les ovogonies deviennent des ovocytes primaires. Elles conservent deux propriétés des cellules en interphase: 


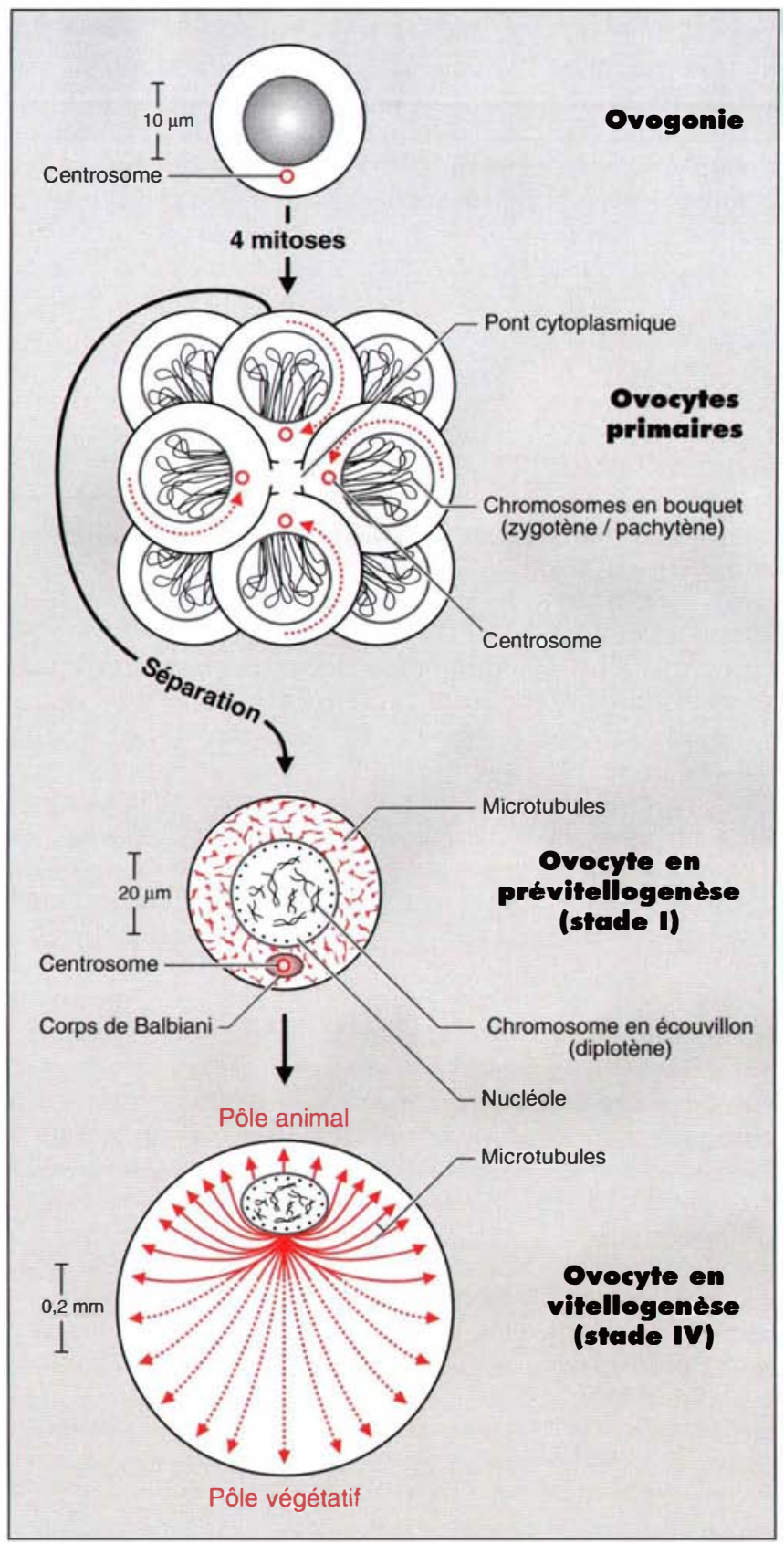
montrées) et commence à grossir. Pendant tout son accroissement, l'ovocyte reste bloqué en phase diplotène. Ses chromosomes prennent un aspect particulier (en écouvillon), tandis que de nombreux nucléoles garnissent la périphérie de la vésicule germinative. L'accroissement est divisé en 6 stades (I à VI). Au stade I, les mitochondries se rassemblent dans une formation juxtanucléaire, que I'on appelle corps de Balbiani. Au stade II, l'ovocyte entre en vitellogenèse. Le corps de Balbiani se disperse, tandis que du pigment et du vitellus commencent à s'accumuler de façon dissymétrique, si bien que l'ovocyte possède désormais deux pôles clairement reconnaissables. Au stade IV, la vésicule germinative se déplace vers le pôle animal. Le cytoplasme devient de plus en plus opaque, ce qui rend difficile l'observation du cytosquelette. Toutefois, on peut reconnaître une organisation globalement radiaire des microtubules. (D'après [23] et [24], modifié.) leur noyau reste entouré d'une membranc et leur centrosome ne se dédouble pas [24]. Le centrosome occupe une position qui dépend de l'orientation de l'ultime division préméiotique. Il impose une polarité transitoire au sein de la vésicule germinative. Durant les phases zygotène et pachytène de la prophase I, les chromosomes se rassemblent en bouquet. Leurs extrémités (télomères) se rapprochent et se placent au contact de la membrane nucléaire, à proximité du centrosome [24].

Quand l'ovocyte commence à s'accroître, son cytoplasme acquiert une polarité manifeste. Une formation arrondie apparaît à proximité de la vésicule germinative: le corps de Balbiani. Il s'agit d'un amas de mitochondries, soudées par une sorte de ciment $[4,25]$. Le corps de Balbiani contient le centrosome [4, 25]. Toutefois, ce dernier ne semble pas constituer un MTOC fonctionnel, qui organiserait les microtubules de l'ovocyte [23, 26].

Au début de la vitellogenèse, le corps de Balbiani se désagrège et ses éléments constitutifs se dispersent (figure 2). Mais il laisse une trace avant de disparaître: le côté où il réside définit le pôle végétatif [27]. Désormais, l'ovocyte n'a plus de centrosome reconnaissable [23]. Sa vésicule germinative se place en position excentrée. Ce mouvement fait participer les microtubules [26]. Ceux-ci adoptent une disposition radiaire qui est plus facile à discerner dans l'hémisphère animal que dans l'hémisphère végétatif, sans doute à cause de l'abondance du vitellus dans la moitié végétative de la cellule. L'ensemble du système aurait une orientation centrifuge: l'extrémité (+) des microtubules serait en position périphérique par rapport à un MTOC principal situé sur la face du noyau qui est tournée vers le pôle végétatif (figure 2).

Il semble donc qu'avant même l'èntrée en méiose, le couple centrosome-noyau impose à la cellule germinale une polarité qu'elle conservera jusqu'à la fin de son accroissement. La polarité se révèle d'abord par la présence du corps de Balbiani. Elle se traduit ensuite par l'accumulation dissymétrique de nombreux consti- 
tuants ovulaires, tels que le vitellus et les déterminants végétatifs (figure 1). Il reste à établir quels mécanismes gouvernent cette accumulation.

\section{Accumulation du vitellus dans l'ovocyte du xénope}

Le vitellus est constitué de lipoprotéines élaborées par les cellules du foie $[21,28]$. Ces protéines apparaissent sous la forme d'un précurseur soluble (la vitellogénine), qui est sécrété dans le courant sanguin. Parvenue dans l'ovaire, la vitellogénine est reconnue par des récepteurs localisés dans la membrane des ovocytes [29]. Ces récepteurs appartiennent à la famille des récepteurs des VLDL (very low density lipoproteins) [30]. Le complexe vitellogénine-récepteur est intégré au niveau de puits recouverts [16]. Il passe ensuite dans les endosomes, puis dans les lysosomes. Libérée de son récepteur, la vitellogénine subit une série de coupures protéolytiques, qui la rendent insoluble et l'entraînent à se condenser en plaquettes. Celles-ci seraient donc des lysosomes modifiés. Comme les lysosomes, les plaquettes vitellines sont limitées par une membrane [10]. Leur contenu est acide [31]. Elles contiennent une protéase typiquement lysosomique : la cathepsine D [32].

Dans les ovocytes en vitellogenèse, le vitellus commence par s'accumuler en périphérie, en une couche uniforme [10]. Il semble donc que la vitellogénine pénètre dans l'ovocyte de manière isotrope. D'autres couches de vitellus s'ajoutent en surface, si bien que les plaquettes déposées en premier lieu finissent par occuper le centre de la cellule [27]. Le vitellus apparu dans l'hémisphère animal se déplace peu à peu vers l'hémisphère végétatif, tandis que le vitellus déposé dans l'hémisphère végétatif reste à cet endroit [10]. Il est probable que le cytosquelette intervient dans la migration des plaquettes, mais on ignore tout $\mathrm{du}$ mécanisme impliqué.

\section{Localisation de I'ARN} dans l'ovocyte de xénope

Le cytosquelette joue un rôle crucial ovulaires. Bien qu'aucun déterminant n'ait été formellement identifié, plusieurs ARN sont de bons candidats pour une telle fonction. Par exemple, l'ARN messager Xcat-2 pourrait être un déterminant germinal $[33,34]$. Cet ARN apparaît dès le début de l'ovogenèse et se concentre dans le corps de Balbiani (figure 3). Lorsque ce dernier se désagrège, l'ARN X cat-2 migrerait vers le pôle végétatif, en suivant une voie tracée par les microtubules, puis s'intégrerait dans les granules polaires.

Le cortex végétatif contient aussi des ARN qui pourraient intervenir dans la morphogenèse somatique: les ARN Vg-1, TGF- $\beta 5$, Wnt11 et Xlsirt. Parmi ces ARN, les trois premiers spécifient des protéines qui pourraient jouer un rôle dans l'induction et la polarisation du mésoderme au début du développement [19, 33, 35]. Comme l'ARN Xcat-2, les ARN Xwnt1 1 et Xlsirt transitent par le corps de Balbiani avant de gagner le pôle végétatif $[34,35]$. Ils seraient entraînés vers leur localisation définitive par des moteurs se déplaçant le long des microtubules. Ils se lieraient ensuite au cytosquelette cortical [33]. En revanche, l'ARN $V g-1$ ne passe pas par le corps de Balbiani. Cet ARN est réparti de manière uniforme dans le cytoplasme des ovocytes en début d'accroissement [36]. Il gagne ensuite l'hémisphère végétatif grâce à un système de transport dépendant des microtubules. On a identifié une protéine de $69 \mathrm{kDa}$ qui se lie aux ARN $V g-1$ et $T G F-\beta 5$, et participerait à leur localisation [33]. Dans le cortex végétatif, l'ARN $V g-1$ est fixé aux microfilaments [36]. L'ancrage nécessite l'ARN Xlsirt, qui n'a pas de phase ouverte de lecture, et n'est donc pas traduisible en protéine [37].

\section{Influence de la gonade sur la polarité ovulaire}

Nous avons vu que chez le xénope et les vertébrés en général, l'ovaire ne semble jouer aucun rôle dans l'établissement de la polarité ovulaire. Dans de nombreux autres groupes d'animaux tridermiques (céphalochordés, urochordés, échinodermes, némertiens, mollusques, annélides, crustacés), les choses se passent différemment: c'est la gonade qui détermine la polarité de l'ovocyte $[4,38]$. Le plus souvent, le pôle végétatif se forme du côté où l'ovocyte est en contact avec la paroi de l'ovaire (figure 4). Il semble que la polarité de l'ovocyte est fixée avant même que le vitellus ne commence à apparaître. On peut supposer que la vésicule germinative et le centrosome s'alignent dans l'axe défini par la zone de contact avec la paroi de l'ovaire (figure 4). C'est peut-être le résultat d'une contrainte mécanique exercée par le follicule. Comme chez le xénope (figure 2), le côté où se place le centrosome définit le pôle végétatif [4].

Dans les ovocytes de nombreux animaux (arachnides, insectes, annélides, etc.), les premiers signes de polarité apparaissent à l'intérieur de la vésicule germinative [4]. Comme chez les amphibiens (figure 2), les chromosomes se disposent en bouquet. Ce dernier s'implante toujours dans la membrane nucléaire à l'endroit le plus proche du centrosome, donc du côté correspondant au futur pôle végétatif de l'ovocyte $[4,39]$.

La polarité de l'ovocyte devient plus évidente dès qu'il commence à s'accroître. Elle est bien visible quand un corps de Balbiani se constitue. Cette formation n'est pas propre aux ovocytes des vertébrés (téléostéens, amphibiens, mammifères). On a pu l'observer chez de nombreux autres animaux: urochordés, échinodermes, arthropodes (arachnides, myriapodes, insectes), mollusques, annélides, platheminthes, acanthocéphales [4, 25]. Son aspect et sa composition sont très variables. D'une manière constante, le corps de Balbiani apparaît comme une région du cytoplasme riche en ARN, contenant le centrosome ainsi qu'un ensemble d'éléments figurés reconnaissables au microscope photonique ou électronique. On y distingue des inclusions lipidiques, des mitochondries et un jeu plus ou moins organisé de vésicules qui seraient impliquées dans l'endocytose ainsi que dans la synthèse et la distribution intracellulaire des protéines (réticulum endoplasmique, appareil de 


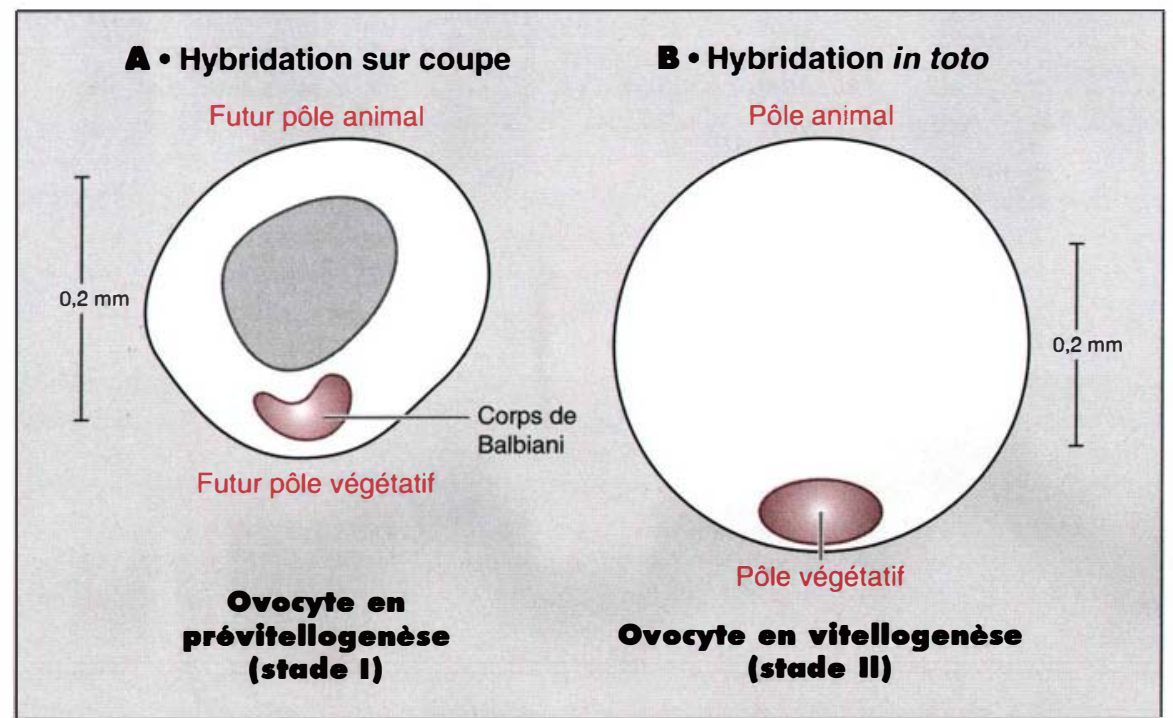

Figure 3. Distribution de I'ARN messager Xcat-2 dans les ovocytes de xénope. L'ARN étudié pourrait être un constituant du plasme germinal. Sa distribution intracellulaire a été déterminée par hybridation in situ dans des ovocytes de stades l et II. La sonde utilisée est une copie "antisens" de I'ARN messager, marquée par la digoxigénine. Le conjugué ARN-digoxigénine est révélé par une réaction antigène-anticorps. Dans l'ovocyte de stade I (A), I'hybridation est faite sur une coupe passant par le corps de Balbiani et la vésicule germinative. On voit que l'ARN (en bistre) est concentré dans la région du corps de Balbiani la plus proche du pôle végétatif. Dans l'ovocyte de stade II (B), I'hybridation est faite in toto, ce qui ne révèle que les molécules localisées dans le cortex de la cellule. L'ARN est réparti en une calotte centrée sur le pôle végétatif (qui est tourné légèrement vers l'observateur). II occupe une position similaire dans l'ovocyte mûr, dont le diamètre est d'environ 1,2 $\mathrm{mm}$. (D’après [35].)

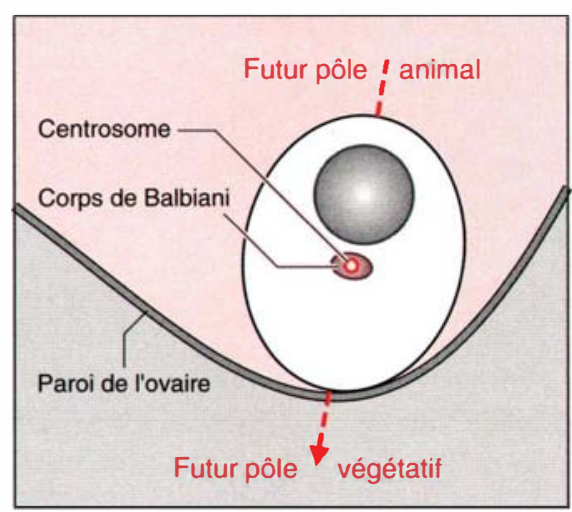

Figure 4. Influence de l'ovaire sur I'orientation de l'ovocyte. Chez les animaux tridermiques, l'ovocyte est entouré d'une gaine complète de cellules folliculaires (non figurées). En s'accroissant, il fait souvent saillie dans la cavité ovarienne, et n'est parfois rattaché à la paroi de l'organe que par un pédoncule. Chez la plupart des invertébrés que l'on a étudiés, la vésicule germinative se place en position distale par rapport à la zone de contact avec la paroi de l'ovaire, tandis que le centrosome et le corps de Balbiani (quand il existe) se trouvent en position proximale. C'est de ce côté qu'apparaît le pôle végétatif. Il faut noter que le corps de Balbiani et le centrosome ne sont visibles que dans les petits ovocytes. Pendant la vitellogenèse, le corps de Balbiani se disperse et le centrosome devient indétectable ou inactif en tant que centre organisateur des microtubules.
Golgi). Suivant les groupes zoologiques, l'un ou l'autre élément prédomine. Le corps de Balbiani n'est pas en contact direct avec la vésicule germinative. Toutefois, certains chercheurs ont décrit des particules nucléoprotéiques qui semblent quitter la vésicule germinative pour construire le corps de Balbiani [25].

En dépit des nombreux travaux qui lui ont été consacrés, la fonction du corps de Balbiani demeure inconnue [25]. On pressent qu'il doit y avoir une relation de cause à effet entre sa position et l'établissement de l'axe animal-végétatif. Le corps de Balbiani pourrait constituer un lieu de convergence pour certains ARN synthétisés dans la vésicule germinative, et pour des protéines destinées à être redistribuées dans le cytoplasme. Mais plusieurs questions demeurent sans réponse. Comment le corps de Balbiani pourrait-il intervenir dans la répartition dissymétrique des protéines endogènes et exogènes? Quel mécanisme provoque sa dispersion quand l'ovocyte atteint une taille suffisante? Quelle trace laisse-t-il dans le cytoplasme après qu'il a disparu?

\section{Polarité des cystes ovariens chez la drosophile}

Les ovules que produisent la plupart des animaux ne possèdent qu'une seule polarité, définissant l'axe primaire de l'embryon. Cependant, les ovules de certains animaux présentent deux polarités: antéro-postérieure et dorso-ventrale [4]. C'est le cas pour les les insectes, et notamment la drosophile.

Dans l'ovocyte de drosophile, c'est la polarité antéro-postérieure qui apparaît en premier lieu. Pour simplifier les choses, on ne décrira ici que la genèse de cette seule polarité. Chez la drosophile, comme chez de nombreux autres insectes, l'ovocyte est aidé dans son accroissement par des cellules nourricières d'origine germinale, qui lui fournissent l'essentiel des molécules et organites nécessaires à sa croissance (figure 5). L'ovogenèse se déroule dans des cystes alignés suivant l'axe antéropostérieur de l'ovaire. Chaque cyste 


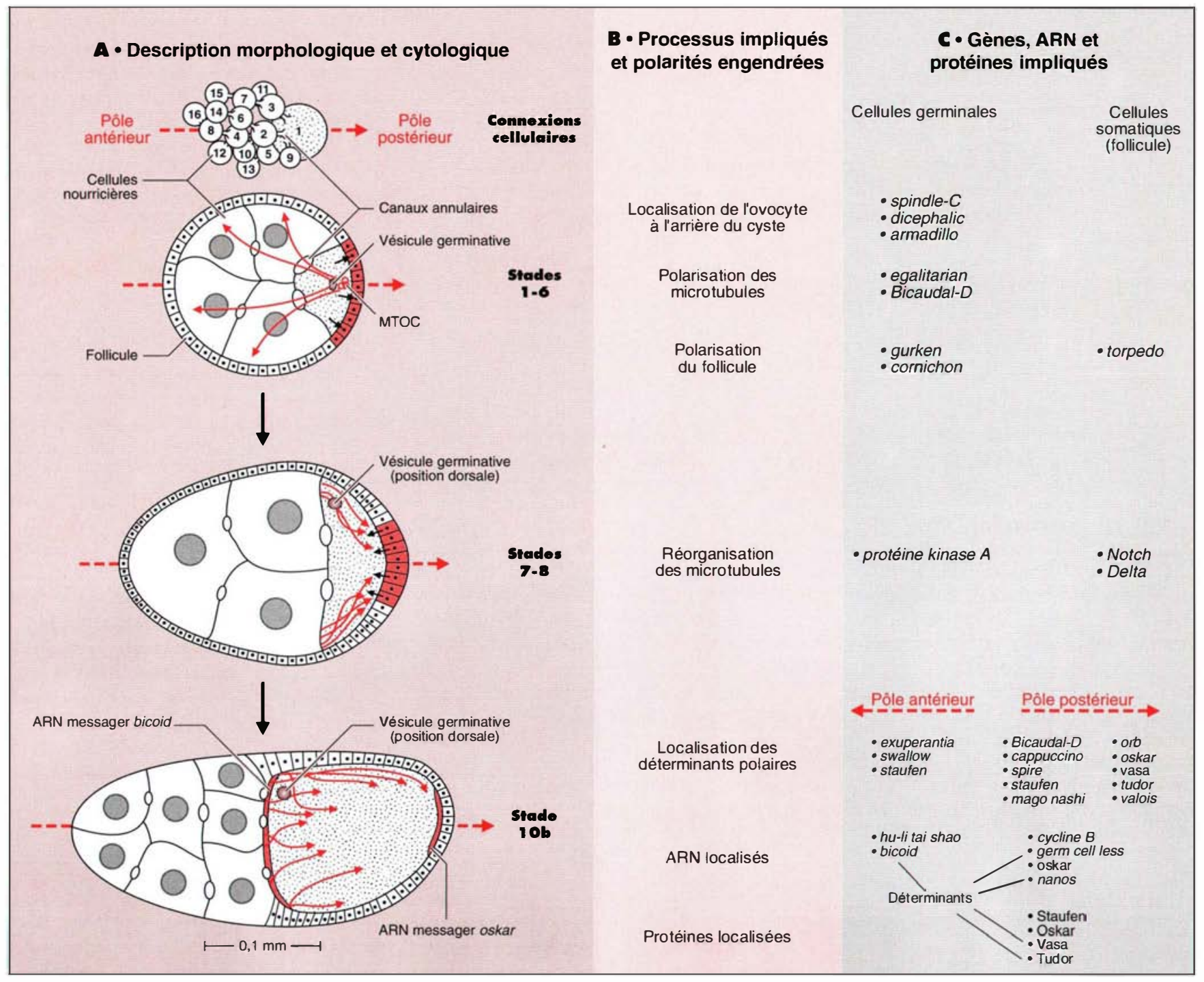

Figure 5. Genèse de la polarité ovulaire chez la drosophile. L'ovogenèse dure environ 8 jours. On la subdivise en 14 stades, qui s'accompagnent de profondes transformations morphologiques (A), faisant intervenir de nombreux processus (B) et de nombreux gènes (C). L'ovogenèse se déroule dans un cyste formé d'un follicule enfermant un ovocyte et 15 cellules nourricières, tous reliés par 1 à 4 ponts cytoplasmiques, appelés canaux annulaires (A). Durant la première partie de l'ovogenèse (stades 1-6), une triple polarité s'instaure dans le cyste ovarien (B). En premier lieu, I'ovocyte se place en arrière du cyste. En deuxième lieu, son MTOC (microtubule organizing center) organise suivant une orientation antéro-postérieure un système de microtubules qui pénètre dans les cellules nourricières, et sert de guide pour l'importation de toutes sortes de matériaux, et notamment d'ARN. En troisième lieu, I'ovocyte polarise le follicule en agissant sur les cellules placées à son contact. Vers le stade 7, le follicule agit à son tour sur l'ovocyte, l'obligeant à réorganiser son appareil microtubulaire et à inverser sa polarité. Dès ce moment, les produits de plusieurs gènes commencent à s'accumuler aux pôles antérieur et postérieur de l'ovocyte, où ils contribuent à édifier le plasme polaire (C). La localisation nécessite l'activité de nombreux gènes (exuperantia, swallow, etc.). Elle a lieu dans un ordre déterminé. Ne sont mentionnés que les ARN et les protéines qui sont localisés à la fin de l'ovogenèse. Certaines de ces macromolécules sont considérées comme des déterminants. (D'après [40-44].)

est limité par une gaine de cellules folliculaires d'origine somatique. Il renferme un clone de 16 cellules sœurs communiquant par leur cytoplasme: 15 cellules nourricières et un ovocyte.
Pour élire en son sein l'unique cellule qui propagera l'espèce, le clone fait agir plusieurs gènes [40]. L'instrument du choix réside dans le fusome, qui est un organite ramifié reliant les cellules du syncytium en formation
$[40,41]$. Le fusome se forme le long des restes des 15 fuseaux élaborés lors des 4 mitoses qui créent le cyste. A chaque division, il transmettrait successivement à l'une des deux cellules filles un facteur la destinant à devenir 
ovocyte [40]. La manière dont se fait la transmission demeure inconnue. Le fusome requiert pour se constituer le produit du gène hu-li tai shao (hts). Dans les cellules somatiques, la protéine Hts est associée au cytosquelette fait partie du fusome [41].

Quand le cyste ovarien est constitué, l'ovocyte se place derrière les cellules qui vont le nourrir (figure 5) [45]. C'est apparemment l'ovaire qui oblige l'ovocyte à adopter cette position. Le mouvement réclame l'action de plusieurs gènes, dont spindle-C, dicephalic et armadillo. Chez certains mutants spindle- $C$ ou armadillo-, l'ovocyte reste localisé au centre du cyste ovarien, entre deux groupes de cellules nourricières [45].

\section{Polarité des ovocytes chez la drosophile}

Dès le début de son accroissement, l'ovocyte possède un système microtubulaire polarisé (figure 5). Au moins deux gènes sont nécessaires pour que cette polarité s'établisse et se maintienne: egalitarian et Bicaudal-D [40]. Le MTOC de l'ovocyte se trouve en position postérieure. Il réunit les centrioles que lui ont cédés - peut-être grâce au fusome - les cellules nourricières. Le produit de Bicaudal-D pourrait participer à l'assemblage du MTOC ovocytaire [40]. Les microtubules s'organisent autour de ce centre nucléateur, suivant une direction privilégiée, qui coïncide avec le futur axe antéro-postérieur de l'œuf [40-43]. Les microtubules se prolongent dans l'ensemble du cyste ovarien (figure 5). L'ovocyte ne se contente pas de communiquer avec les cellules nourricières. Il agit sur les cellules folliculaires placées à son contact, grâce aux produits des gènes gurken et cornichon (figure 5). La protéine Gurken véhicule le signal émis par l'ovocyte [44]. Cette protéine est homologue du facteur de croissance TGF $\alpha$ (transforming growth factor $\alpha$ ) [44]. Les cellules folliculaires perçoivent le message au moyen de la protéine Torpedo, qui est un récepteur de type tyrosine kinase, homologue du récepteur de l'EGF (epithelial growth factor) [44].

Plus tard, le follicule envoie à l'ovocyte un signal en retour qui induit un cortical. Dans les cystes ovariens, elle

changement de polarité dans l'appareil microtubulaire (figure 5). La transmission du signal fait intervenir dans le follicule les protéines Notch et Delta, suivant un mécanisme qui reste mal compris. Dans l'ovocyte, le signal active une protéine kinase dépendante de l'AMP cyclique [44]. En conséquence, les microtubules se réorganisent. Le MTOC postérieur disparaît. Un système microtubulaire se reconstitue sous le cortex, à partir de MTOC résidant sur la face antérieure de l'ovocyte [40-43]. Les microtubules ont maintenant une polarité inversée: au lieu d'orienter leur extrémité (+) vers l'avant, ils la tournent vers l'arrière.

Pendant la phase finale de l'ovogenèse (non montrée), le cytoplasme des cellules nourricières se déverse rapidement dans l'ovocyte [40-42]. Les microfilaments provoquent dans les cellules nourricières des contractions qui en expulsent le contenu. Les produits de plusieurs gènes sont requis pour que le processus se produise normalement [41]. Le cytoplasme de l'ovocyte est lui-même le siège d'une agitation intense. L'appareil microtubulaire y déclenche un mouvement giratoire qui brasse les éléments nourriciers qui affluent de toutes parts [41]. Certains de ces éléments se localisent en des endroits précis.

\section{Localisation des déterminants dans l'ovocyte de drosophile}

Comme celui de xénope, l'œuf de drosophile possède un plasme

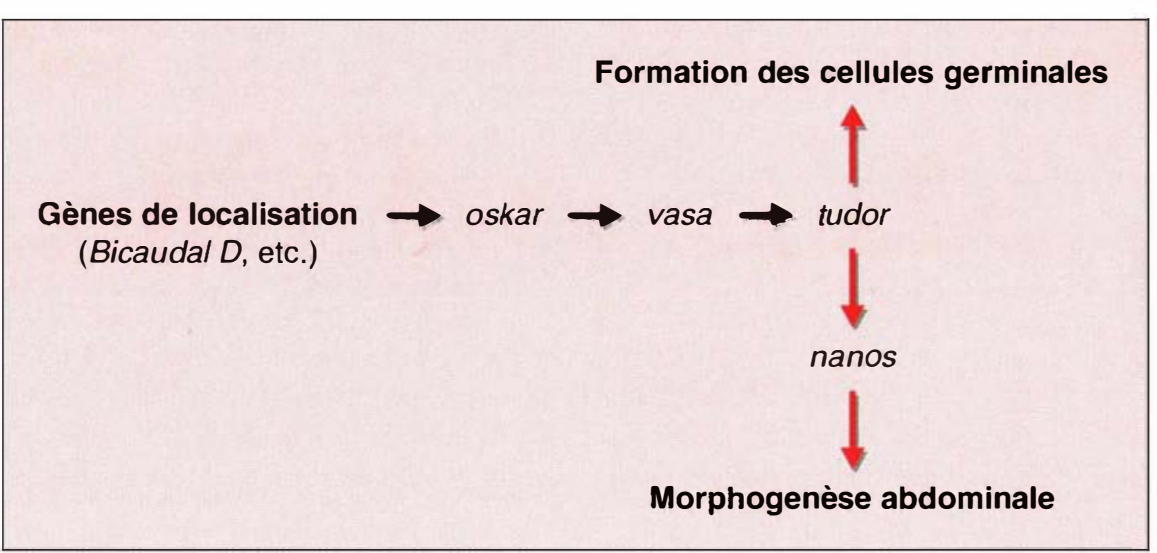

polaire qui remplit une double fonction: germinale et somatique. Le plasme polaire est situé au pôle postérieur. Il contient plusieurs déterminants germinaux (les produits des gènes germ cell less, vasa et tudor), qui sont probablement intégrés dans les granules polaires [47]. Le plasme renferme aussi un déterminant somatique essentiel, qui est l'ARN messager nanos [48]. D'autres macromolécules font partie du plasme polaire: les ARN cycline B et oskar, ainsi que les protéines Staufen et Oskar (figure 5). On a identifié par mutagenèse plusieurs gènes dont les produits sont requis pour la localisation des déterminants au pôle postérieur de l'ovocyte: Bicaudal D, cappuccino, spire, staufen, etc. (figure 5). Les produits d'oskar, vasa et tudor sont impliqués dans la localisation des déterminants, tout en appartenant au plasme polaire $[47,49]$. En fait, ces produits participent à l'assemblage des divers éléments du plasme [44].

L'ARN messager oskar est un des premiers à se concentrer dans la région postérieure de l'ovocyte (figure 5). Cet ARN est synthétisé par les cellules nourricières et pénètre dans l'ovocyte par l'avant. Après la réorganisation du cytosquelette (figure 5), l'ARN oskar est transporté vers l'arrière le long des microtubules [50]. On pense que le transport est assuré par une particule contenant, outre l'ARN lui-même, un moteur de type kinésine, ainsi que diverses protéines servant à attacher l'ARN au moteur et à empêcher sa traduction prématurée [50]. La protéine Staufen fixerait l'ARN oskar au moteur en 
se liant à la partie 3'-terminale (non traduite) de sa séquence, tandis que la protéine spécifiée par le gène bruno inhiberait la traduction de l'ARN oskar [44]. Ce dernier n'est traduit qu'après avoir atteint sa localisation définitive. La protéine Oskar participerait à l'ancrage de son propre ARN messager aux microfilaments de la région polaire $[44,51]$.

D'autres constituants du plasme polaire seraient localisés par un mécanisme différent. Certains ARN sont d'abord distribués de manière uniforme dans le cytosplasme de l'ovocyte (comme l'ARN $V g$ - 1 chez le xénope). Le brassage du cytoplasme les amènerait au contact de quelque élément déjà ancré au pôle postérieur, qui les retiendrait et les préserverait de la dégradation [50].

L'analyse génétique a révélé la double influence qu'exercent sur le développement les gènes de localisation postérieure (Bicaudal D., etc.) [44, 47, 50]. L'inactivation de l'un d'entre eux affecte la formation de la lignée germinale et la morphogenèse de l'abdomen. Tous les gènes concernés sont exprimés durant l'ovogenèse. On a mis en évidence une chaîne d'interactions géniques que l'on peut schématiser par une série de flèches signifiant qu'une mutation dans un gène provoque une localisation incorrecte des produits des gènes situés en aval:

Il y a un autre foyer de morphogenèse au pôle antérieur de l'œuf et de l'embryon [48]. Il semble que des mécanismes semblables sont utilisés pour localiser à l'arrière les déterminants germinaux et postérieurs, et à l'avant les déterminants antérieurs, dont le principal est l'ARN messager bicoid (figure 5) [50]. Le système de localisation antérieure comporterait un moteur de type dynéine, ainsi que la protéine Staufen [43, 48].

\section{Caractères singuliers de l'ovogenèse chez la drosophile}

On voit que l'étude de la drosophile a livré de nombreux détails concernant la genèse de la polarité ovulaire (figure 5). Toutefois, il faut garder à l'esprit sente de nombreux caractères qui paraissent dérivés, et ne sont donc pas généralisables à l'ensemble des animaux. En premier lieu, l'ovocyte est pourvu de cellules nourricières. En deuxième lieu, la polarité des microtubules change au cours de l'ovogenèse, ce qui est peut-être lié au mode de nutrition particulier de l'ovocyte. En troisième lieu, l'œuf a une forme allongée. En quatrième lieu, l'œuf possède plusieurs foyers de morphogenèse, tandis que les oufs de forme arrondie n'en ont apparemment qu'un.

Tout n'est probablement pas dérivé dans l'ovogenèse de la drosophile. Il se pourrait que l'organisation unidirectionnelle des microtubules constituât un caractère général. Durant la phase ultime de son accroissement, l'ovocyte a un système microtubulaire orienté vers le pôle postérieur, qui correspond au pôle végétatif dans les oufs de forme sphérique (figure 5). Ces microtubules guident plusieurs déterminants vers le pôle postérieur. Il est possible que dans les ovocytes de forme arrondie, une partie de l'appareil microtubulaire possède également une orientation privilégiée, et serve au transport des déterminants vers le pôle végétatif.

\section{Polarité de la blastula}

Chez la plupart des métazoaires, la fécondation déclenche dans l'œuf une suite rapide de divisions. En général, les deux premiers plans de division sont orthogonaux (figure 6). L'œuf segmenté a souvent la structure d'une coeloblastula. Celle-ci se présente comme un épithélium de cellules ciliées, délimitant une cavité (le blastocœle). Chez beaucoup d'animaux, la polarité de la blastula se marque par la position excentrée de la cavité blastocoelienne. Cette dissymétrie vient du fait que les blastomères animaux, moins chargés en vitellus, deviennent rapidement plus petits que les blastomères végétatifs, bien que tous se divisent de manière à peu près synchrone jusqu'à un stade connu sous le nom de transition blastuléenne $[2,10,52]$.

La segmentation conduit les blastomères à s'organiser en épithélium. Il faut donc que dans chacun d'eux, le cytosquelette adopte progressivement l'organisation typique des cellules épithéliales. Durant la segmentation, les microtubules sont périodiquement mobilisés par les centrosomes pour construire les fuseaux mitotiques (figure 6). A la fin du processus, leur polarité s'est globalement inversée: de centrifuge dans l'œuf, elle est devenue centripète dans l'épithélium blastuléen. Ce renversement tient au fait que dans chaque cellule de la blastula, le MTOC s'éloigne du noyau et s'installe en position apicale. Quant aux microfilaments, ils désertent la face apicale et se réorganisent de façon à permettre l'ancrage des jonctions intercellulaires. Les parois latérales se couvrent de molécules adhésives, parmi lesquelles la cadhérine $\mathrm{E}$ semble jouer un rôle essentiel [53].

Bien que l'appareil microtubulaire se réorganise en permanence au cours de la segmentation (figure 6), il semble que cela affecte assez peu la position des déterminants ovulaires, car ceux-ci sont liés aux microfilaments corticaux, qui ne sont pas mobilisés par les centrosomes. La localisation périphérique des déterminants obéit probablement à une nécessité, qui est de garantir un référentiel relativement stable pendant une période de grande agitation cytoplasmique. Ce référentiel ne pourrait pas exister si les déterminants étaient attachés aux microtubules. C'est donc à la surface de l'œuf et de la blastula que se trouvent les territoires correspondant aux principaux organes de l'embryon [2]. Le cortex porte une carte des territoires présomptifs, qui est en quelque sorte un plan bidimensionnel de l'embryon à construire. En général, la carte définit l'axe primaire de l'embryon. Elle donne des indications plus précises quand le développement présente un caractère "mosaïque», comme celui des annélides [6].

\section{Retour aux sources}

Beaucoup de zoologistes pensent que tous les métazoaires dérivent d'un ancêtre commun, qui était structuré comme une blastula [54]. Ce précurseur hypothétique a été appelé blastaea par Haeckel. En fait, la blastaea représente le métazoaire le plus 


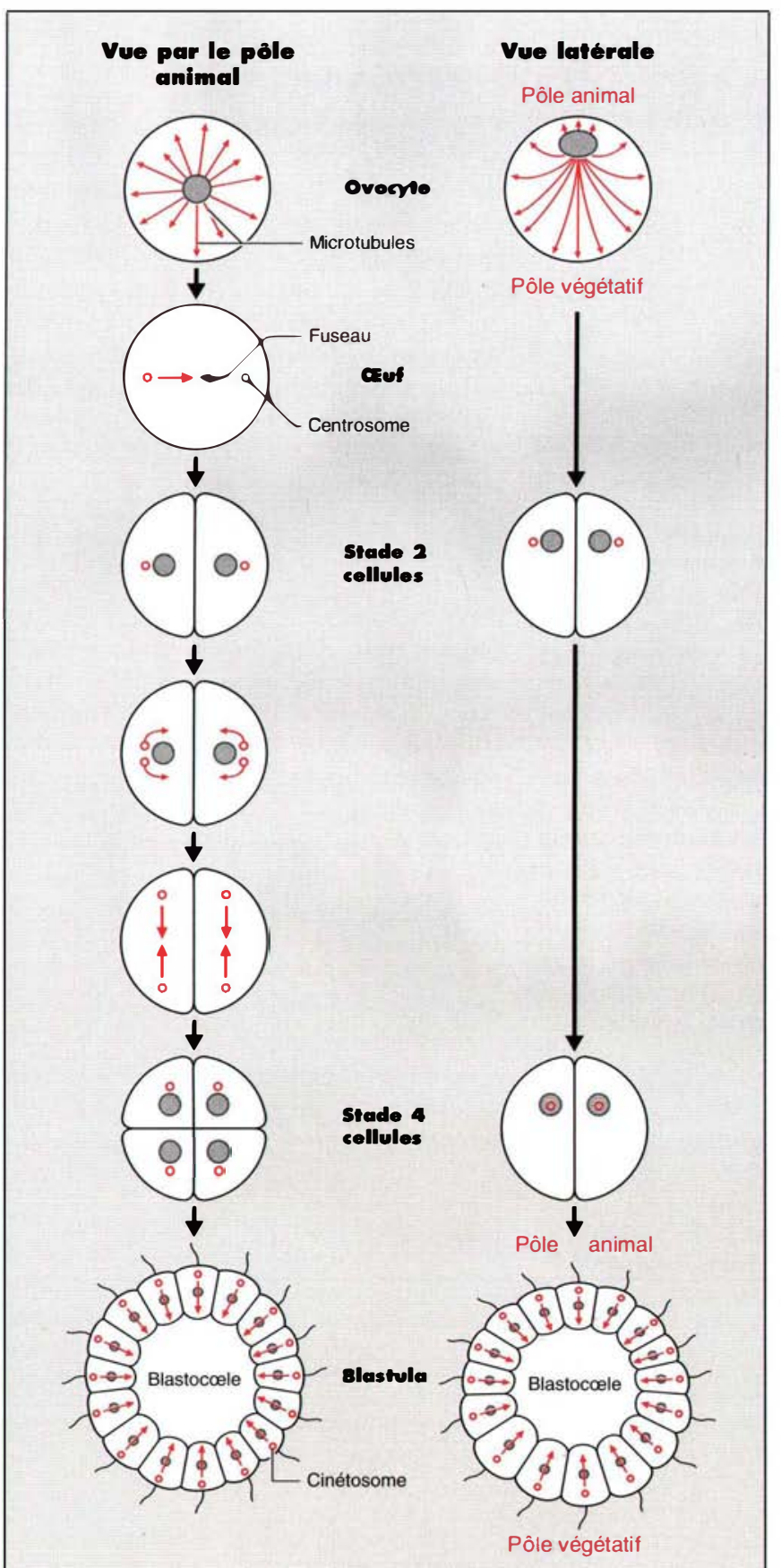
somes fils, qui migrent d'un quart de tour en s'éloignant l'un de l'autre, ce qui détermine un deuxième plan de division, perpendiculaire au premier. Les divisions suivantes se poursuivent selon des orientations variables d'un groupe zoologique à l'autre. Dans les cas les plus simples, la segmentation crée une blastula creuse, ou cœloblastula. Celle-ci se compose d'un épithélium de cellules ciliées, portant un cinétosome à la base de chaque cil. Dans les cellules de la blastula, au moins une partie des microtubules est orientée de manière que les extrémités (-) se trouvent du côté apical (extérieur), où réside le cinétosome. L'épithélium blastuléen doit donc avoir un appareil microtubulaire à orientation centripète. Celle-ci est schématisée sur des coupes passant par le plan équatorial (à gauche) ou par un plan méridien (à droite). simple qui se puisse concevoir, puisqu'elle est censée ne comporter que deux types cellulaires, formant un soma et un germen [54]. Tout porte à croire que la blastaea pratiquait la reproduction sexuée et se développait à partir d'un œuf. Son embryogenèse devait donc se limiter à une différenciation des cellules en deux catégories [54].

Comment la blastaea pouvait-elle orienter la différenciation de ses cellules dans deux directions? Pour y parvenir, il a peut-être suffi de faire apparaître un plasme germinal dans l'œuf [54]. Cette idée a une implication évidente: les organismes de type blastaea produisaient déjà des oufs polarisés parce que le plasme germinal occupait une zone définie du cortex. Cette dissymétrie serait la manifestation la plus ancienne de la polarité ovulaire. C'est la position du plasme germinal qui détermine celle du pôle végétatif.

Pour localiser les déterminants germinaux en un endroit précis du cortex ovulaire, il faut que le cytosquelette de l'ovocyte soit polarisé. Un modèle simple de polarité ovulaire attribue un rôle important aux microtubules (figure 7). On suppose que dans les ovocytes des premiers métazoaires, une partie des microtubules était orientée suivant une direction privilégiée. Le centrosome ou la vésicule germinative servait de centre de nucléation pour un faisceau de microtubules dirigé vers le point le plus proche de la paroi cellulaire. Cet endroit devient le pôle végétatif. Une voie de migration préférentielle est ainsi créée pour les déterminants germinaux synthétisés dans la vésicule germinative ou dans le cytoplasme. Un moteur de type kinésine entraîne les déterminants vers le pôle végétatif. Parvenus à destination, les déterminants s'attachent au cortex ovulaire, en s'arrimant aux microfilaments d'actine, qui sont eux-mêmes liés par l'intermédiaire de diverses protéines à la membrane plasmique [55]. Lorsque l'œuf se segmente, le plasme germinal est inclus dans les blastomères végétatifs. Ces blastomères fondent la lignée germinale.

Le schéma évolutif proposé (figure 7) attribue au plasme germinal une ori- 


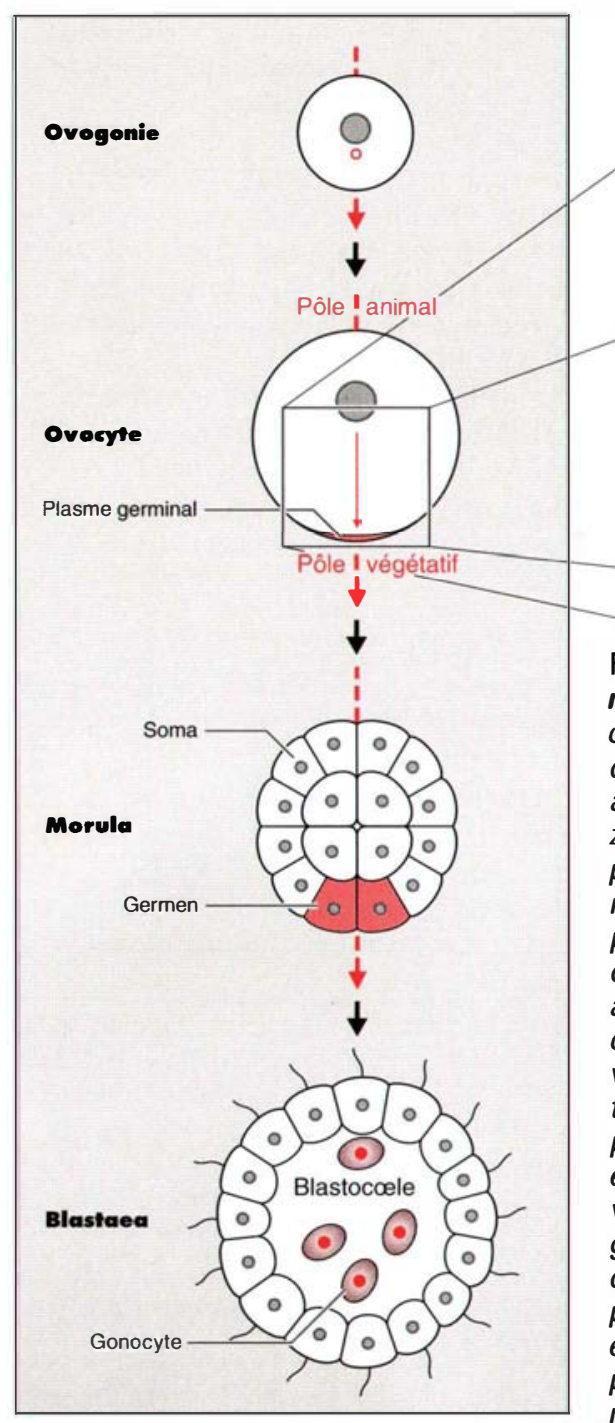
Parvenus à proximité de la membrane plasmique, les déterminants s'attachent aux microfilaments corticaux, ce qui crée un plasme germinal. Quand l'œuf se segmente, le plasme se répartit entre les blastomères, et fait évoluer en gonocytes les cellules qui les intègrent. Ces cellules entrent dans le blastocœle parce qu'elles n'acquièrent pas les molécules adhésives nécessaires pour leur insertion dans l'épithélium blastuléen. Toutes les autres cellules édifient le soma. Le modèle n'attribue aucun rôle au corps de Balbiani. II n'indique pas comment les déterminants germinaux déclenchent dans les gonocytes le programme génétique qui les transformera en ovules ou en spermatozoïdes. II ne précise pas non plus comment les gamètes sont libérés du blastocœle.

gine très ancienne. Chez certains animaux, il semble que des éléments de ce plasme sont synthétisés dès le début de l'ovogenèse. C'est le cas pour le xénope, où de tels éléments apparaissent plus d'un an avant que l'ovocyte ne cesse de s'accroître (figures 2 et 3). Pareille hâte est peutêtre le souvenir d'un événement évo- lutif très reculé. En termes récapitulatifs, cela pourrait signifier que chez les métazoaires primitifs, l'ovogenèse se déroulait en peu de temps. Ces animaux produisaient de petits œufs, mais pourvus d'un plasme germinal. Par la suite, l'ovogenèse se serait allongée. L'ovocyte aurait mis ce délai à profit pour accumuler du vitellus.

\section{Conclusion et perspectives}

Tout indique que la polarité ovulaire procède de la dissymétrie constitutive qu'imprime dans le cytosquelette la position unilatérale du centrosome vis-à-vis du noyau. En cette matière, la blastaea aurait réalisé une innovation essentielle, consistant à spécialiser les microtubules de l'ovocyte dans le transport des déterminants vers le pôle végétatif, et les microfilaments dans la rétention de ces molécules en un lieu précis du cortex.

Cette hypothèse incite à s'interroger sur la manière dont se localisent les déterminants pendant l'ovogenèse des animaux actuels. A cet égard, beaucoup de questions demeurent sans réponse. Existe-t-il dans les ovocytes de forme sphérique une voie privilégiée pour la migration des déterminants, consistant par exemple en un faisceau de microtubules orienté suivant l'axe animal-végétatif? Le cortex de l'ovocyte a-t-il sur toute sa surface des propriétés uniformes? Ou bien le cortex végétatif possède-til des propriétés particulières, le rendant apte à retenir les déterminants ? Il faut espérer que les recherches en cours permettront rapidement de résoudre ces problèmes

\section{Remerciements}

L'auteur remercie Leonardo Basco, Alain Collenot, Jean-Claude Lacroix, Jean-Claude Mounolou, Jean-Marie Vernier et Maurice Wegnez pour leurs conseils pendant la rédaction de cet article.

\section{Herman Denis}

Professeur à l'université Pierre-et-MarieCurie, Centre de génétique moléculaire Cnrs, avenue de la Terrasse, 91198 Gifsur-Yvette Cedex, France.

\section{TIRÉS À PART}

H. Denis. 


\section{RÉFÉRENCES}

1. Buss LW. The evolution of individuality. Princeton: Princeton University Press, 1987.

2. Davidson EH. Gene activity in early development. Orlando: Academic Press, 1986.

3. Holland LZ, Holland ND. Early development in the lancelet (= Amphioxus) Branchiostoma floridae from sperm entry through pronuclear fusion : presence of vegetal pole plasm and lack of conspicuous ooplasmic segregation. Biol Bull 1992 ; 182 : 77-96.

4. Raven CP. Oogenesis. Oxford: Pergamon, 1961.

5. Hyman LH. The Invertebrates : Protozoa through Ctenophora. New York: McGraw-Hill, 1940 .

6. Anderson DT. Embryology and phylogeny in Annelids and Arthropods. Oxford: Pergamon Press, 1973.

7. Kimble J. An ancient molecular mechanism for establishing embryonic polarity? Science 1994 ; 266 : 577-8.

8. Huxley JS, de Beer MA. The elements of experimental embryology. Londres: Cambridge University Press, 1934

9. Bounoure L. La lignée germinale chez les batraciens anoures. In: Wolff E, ed. L'origine de la lignée germinale. Paris: Hermann, 1964: 205-34.

10. Gilbert SF. Developmental biology. Sunderland: Sinauer, 1994

11. Holwill S, Heasman J, Crawley CR, Wylie CC. Axis and germ line deficiencies caused by u.v. irradiation of Xenopus oocytes cultured in vitro. Development 1987; 100: 735-43.

12. Denis H, Collenot A. L'origine et l'évolution de la reproduction sexuée. médecine/sciences 1993; 9: 1392-403.

13. Carré D, Rouvière C, Sardet C. In vitro fertilization in Ctenophores : sperm entry, mitosis and the establishment of bilateral symmetry in Beroe ovata. Dev Biol $1991 ; 147$ : 381-91

14. Goldstein B, Hird SN. Specification of the anteroposterior axis in Caenorhabditis elegans. Development 1996 ; 122: 1467-74.

15. White J, Strome S. Cleavage plane specification in C. elegans: how to divide the spoils. Cell $1996 ; 84: 195-8$.

16. Alberts B, Bray D, Lewis J, Raff $M$, Roberts K, Watson JD. Biologie moléculaire de la cellule. Paris : Flammarion, 1990.

17. Zheng Y, Wong ML, Alberts A, Mitchison $T$. Nucleation of microtubule assembly by a $\gamma$-tubulin-containing ring complex. Nature 1995 ; 378: 578-83.

18. Bloom GS. Motor proteins for cytoplasmic microtubules. Curr Op Cell Biol 1992; 4 : 66-73.
19. Wilhelm JE, Vale RD. RNA on the move: the mRNA localization pathway. $I$ Cell Biol 1993; 123 : 269-74.

20. Matsudaira P. Modular organization of actin crosslinking proteins. Trends Biochem Sci 1991 ; 16: 87-92.

21. Denis H, Lacroix JC. Une interprétation évolutive de la gamétogenèse animale. médecine/sciences 1993; 9: 752-61.

22. Callen JC, Dennebouy N, Mounolou JC. Kinetic analysis of entire oogenesis in Xenopus laevis. Dev Growth Differ $1980 ; 22$ : 831-40.

23. Gard DL. Organization, nucleation, and acetylation of microtubules in Xenopus laevis oocytes: a study by confocal immunofluorescence microscopy. Dev Biol 1991; 143 : 346-62.

24. Klymkowsky M, Karnovsky A. Morphogenesis and the cytoskeleton: studies of the Xenopus embryo. Dev Biol 1994; 165 : $372-84$.

25. Guraya $S$. Recent advances in the morphology, cytochemistry, and function of Balbiani's vitelline body in animal oocytes. Int Rev Cytol 1979 ; 59 : 249-321.

26. Gard DL, Affleck D, Error BM. Microtubule organization, acetylation, and nucleation in Xenopus laevis oocytes: II. A developmental transition in microtubule organization during early diplotene. Dev Biol 1995; 168: 189-201.

27. Callen JC. Differential pinocytosis and the origin of the animal-vegetal polarity in Xenopus laevis oocytes of growing or postspawning adult females. Biol Cell $1986 ; 57$ 207-20.

28. Byrne BM, Gruber M, Ab G. The evolution of egg yolk proteins. Prog Biophys Molec Biol 1989; 53: 33-69.

29. Stifani S, Nimpf J, Schneider WJ. Vitellogenesis in Xenopus laevis and chicken cognate ligands and oocyte receptors. $J$ Biol Chem 1990 ; 265 : 882-8.

30. Bujo H, Hermann $\mathbf{M}$, Kaderli MO Jacobsen L, Sugawara S, Nimpf J, Yamamoto T, Schneider WJ. Chicken oocyte growth is mediated by an eight ligand binding repea member of the LDL receptor family. $E M B O$ I 1994; 13 : 5165-75.

31. Fagotto F, Maxfield FR. Yolk platelets in Xenopus oocytes maintain an acidic interna $\mathrm{pH}$ which may be essential for sodium accumulation. I Cell Biol 1994; 125 : 1047-56.

32. Retlek H, Steyrer E, Sanders EJ, Nimpf J, Schneider WJ. Molecular cloning and functional characterization of chicken cathepsin D, a key enzyme for yolk formation. $D N A$ Cell Biol $1992 ; 11: 661-72$.

33. Ding D, Lipshitz HD. Localized RNAs and their functions. BioEssays 1993; 15:651-8.

34. Forristall C, Pondel M, Chen L, King ML Patterns of localization and cytoskeletal association of two vegetally localized RNAs, Vgl and Xcat-2. Development $1995 ; 121$ : 201-8.
35. Kloc M, Etkin LD. Two distinct pathways for the localization of RNAs at the vegetal cortex in Xenopus oocytes. Development 1995 ; $121: 287-97$

36. Ysraeli JK, Sokol S, Melton DA. A twostep model for the localization of maternal mRNA in Xenopus oocytes: involvement of microtubules and microfilaments in the translocation and anchoring of Vg1 mRNA. Development 1990; 108: 289. 98.

37. Kloc M, Etkin LD. Delocalization of Vgl mRNA from the vegetal cortex in Xenopus oocytes after destruction of Xlsirt RNA. Science 1994; 265 : 1101-3.

38. Child CM. Patterns and problems of development. Chicago: University of Chicago Press, 1941

39. Denburg AF, Sedat JW, Cande WZ, Bass HW. Cytology of telomeres. In: Blackburn EH, Greider CW, eds. Telomeres. Cold Spring Harbor: Cold Spring Harbor University Press, 1995 : 295-338.

40. Theurkauf WE. Microtubules and cytoplasm organization during Drosophila oogenesis. Dev Biol 1994; 165 : 352-60.

41. Mahajan-Miklos S, Cooley L. Intercellular cytoplasm transport during Drosophila oogenesis. Dev Biol 1994; 165 : 336-51.

42. Cooley L, Theurkauf WE. Cytoskeletal functions during Drosophila oogenesis. Science 1994 ; 266 : $590-6$.

43. Micklem DR. mRNA localization during development. Dev Biol 1995 ; 172 : 377-95.

44. Rongo C, Lehmann R. Regulated synthesis, transport and assembly of the Drosophila germ plasm. Trends Genet 1996; 12: 102-9.

45. Gonzalez-Reyes A, St Johnston D. Role of oocyte position in establishment of anterior-posterior polarity in Drosophila. Science 1994; 266: 639-42

46. Schweisguth F, Israël A. Signalisation intracellulaire par le récepteur Notch. Conservation de la drosophile aux mammifères. médecine/sciences $1996 ; 12$ : 155-63.

47. Strome $S$. The germ of the issue. Nature 1992 ; 358: 368-9

48. St Johnston D, Nüsslein-Volhard C. The origin of pattern and polarity in the Drosophila embryo. Cell 1992; 68 : 201-19.

49. Wilson JE, Macdonald PM. Formation of germ cells in Drosophila. Curr Op Genet Dev $1993 ; 3: 562-5$.

50. St Johnston D. The intracellular localization of messenger RNAs. Cell 1995; 81 : 16170 .

51. Tetzlaff MT, Jäckel H, Pankratz MJ. Lack of Drosophila cytoskeletal tropomyosin affects head morphogenesis and the accumulation of oskar mRNA required for germ cell formation. $E M B O J 1996$; 15 : 1247-54. 


\section{RÉFÉRENCES}

52. Condamine $\mathrm{H}$. L'induction mésodermique et la dorsalisation de l'embryon d'amphibien. médecine/sciences 1992; 8 :37981 .

53. Eaton S, Simons K. Apical, basal, and lateral cues for epithelial organization. Cell $1995 ; 82: 5-8$.

54. Denis H, Mignot JP. L'origine des métazoaires. médecine /sciences $1994 ; 10: 551-63$.

55. Dubreuil RR. Structure and evolution of the actin crosslinking proteins. BioEssays 1991 ; 13: 219-26.

\section{Summary}

Cytoskeleton and egg polarity

The eggs of most Metazoa are highly asymmetrical. A typical metazoan egg is spherical or spheroidal in shape, but has animal and vegetal poles which are easy to distinguish. Egg polarity is thought to be a primitive feature, acquired by a common ancestor of all living Metazoa. Presumably this precursor was a two-cell type organism, comprising a soma and a germ line. The alleged ancestor developed by a simple, two-way cell differentiation process driven by factors localized in egg cytoplasm. Egg polarity probably arose as a consequence of the basic asymmetry imposed on all animal cells by the position of the centrosome with respect to the nucleus. It is proposed that in oocytes of the earliest Metazoa the centrosome-nucleus pair induced a bipolar organization, defining an animal-vegetal axis. The animal pole is the site near which the cell nucleus lies, and where the polar bodies are emitted. The vegetal pole forms on the side of the cell defined by the initial position of the centrosome. It is further argued that a cytoskeleton-based localization system was used to concentrate a special type of macromolecules near the vegetal pole of the oocyte. These macromolecules become sequestered by a fraction of embryonic cells, causing them to differentiate along the germ line.

\section{( \\ Association Française de Lutte contre LA MUGOVISGT. OSE $\prod_{1} \longrightarrow$ \\ DIRECTEUR SCIENTIFIQUE}

Le directeur scientifique dirige l'activité scientifique de l'AFLM, dont le seul objectif est de vaincre, le plus vite possible, la mucoviscidose.

\section{DÉVELOPPEMENT, ANIMATION,}

\section{DIRECTION DES PROGRAMMES DE RECHERCHE}

Le directeur scientifique a pour mission, en collaboration étroite avec le conseil scientifique de l'AFLM, d'identifier et de sélectionner les axes de recherche pertinents dans une perspective thérapeutique pour la mucoviscidose.

Il oriente sur ces sujets les efforts de la recherche en France et à l'étranger.

Il développe des programmes (thérapie génique, pharmacologie des transports ioniques, etc.).

Il stimule l'implication de nouvelles équipes dans le champ de la mucoviscidose.

Il assure la promotion des réseaux de recherche pluridisciplinaires et facilite leur mise en place.

Il agit en liaison étroite avec les principaux organismes de recherche (Inserm, Cnrs, Institut Pasteur, universités, etc.), avec les laboratoires de l'industrie privée et avec ses homologues des associations étrangères (notamment en Amérique du Nord et en Europe).

Il travaille également en liaison étroite avec le directeur à l'action thérapeutique de l'AFLM. Il assure la diffusion des informations scientifiques auprès de la communauté scientifique et du grand public, ainsi que des patients et des familles concernées par la mucoviscidose.

\section{ADMINISTRATION}

Le directeur scientifique est responsable de la préparation des appels d'offres scientifiques et de leur gestion administrative.

Il prépare les réunions du conseil scientifique.

Il organise des congrès, colloques, séminaires pour l'AFLM.

Il est responsable du budget du département scientifique.

\section{COLLECTE DE FONDS}

Le directeur scientifique participe aux actions de collecte de fonds, notamment auprès des pouvoirs publics et des entreprises privées et à l'occasion de diverses manifestations.

\section{POSITION}

Le directeur scientifique dépend du Bureau du conseil d'administration de l'AFLM, en liaison avec le président du conseil scientifique et en collaboration étroite avec le directeur général. Il s'appuie sur un secrétariat.

Le poste est à Paris, au siège de l'AFLM.

\section{RÉMUNÉRATION}

Salaire compétitif pour un candidat de valeur.

Possibilité de détachement de la fonction publique.

\section{PROFIL DU CANDIDAT RECHERCHE}

$L ' A F L M$ recherche avant tout un " animateur "

Doctorat ès sciences et/ou doctorat en médecine.

Expérience de la recherche scientifique et médicale indispensable.

Une expérience de l'administration de la recherche sera appréciée.

Pratique courante de l'anglais indispensable.

Rigueur, sens de l'organisation, capacité à travailler en équipe (notamment dans un contexte associatif) et qualités relationnelles.

Adresser lettre de candidature et résumé de carrière au Président de l'AFLM, 76, nue Bobillot, 75013 Paris

Reconnue d'utilité publique - CCP 617426 W Paris - Meınbre de l'Association Internationale contre la Mucoviscidose Siège : 76, rue Bobillot - 75013 Paris - Tél. : (1) 40.78.91.91 - Fax : (1) 45.80.86.44 